\title{
Pathogenesis Diagnosis, Immune Responses, and Current Treatment Strategies of COVID-19
}

\author{
Jabir Ali ${ }^{1}$, Ujalla Tanveer ${ }^{1}$, Mohsin Raza ${ }^{1}$, Maheen Shafiq ${ }^{1}$, Ghulam Nabi ${ }^{2}$, Suliman \\ $\mathrm{Khan}^{3}$, and Hafiz Muhammad Asmar Naeem ${ }^{4}$ \\ ${ }^{1}$ University of Agriculture Faisalabad \\ ${ }^{2}$ Hebei Normal University College of Life Sciences \\ ${ }^{3}$ Zhengzhou University \\ ${ }^{4}$ Affiliation not available
}

May 29, 2020

\begin{abstract}
Abstract An ongoing novel highly contagious pneumonia outbreak started in Wuhan, which is sprawling capital of central china's province, Hubei, at the late December 2019. World Health Organization on February 12, 2020 officially named this disease as Coronavirus Disease 2019 (COVID-19) caused by Severe Acute Respiratory Syndrome Coronavirus 2 (SARS-CoV-2). The primary host of SARS-CoV-2 is linked with bat specie however; the intermediate host is still not clear. The COVID-19 spread rapidly across the world because of person-person transmission. The SARS-CoV-2 stimulates both the cellular and humoral immunity mediated by viral specific B and T cells. Cases of COVID-19 infection exhibit several clinical complications for example fever, tiredness and dry cough. Diagnosis are mostly depending on epidemiological characteristics, clinical manifestation, and few through the examination of auxiliary tissues. In this review, we have provided a brief introduction of SARS-CoV-2, pathogenesis, diagnosis, immune responses, and treatments and future perspectives.
\end{abstract}

\section{Summary:}

SARS-CoV-2 is a highly contagious member of $\beta$ coronaviruses. It can cause pneumonia like disease officially named by WHO as COVID-19. It infects the persons of all ages children, adults and olds. Primarily it was emerged in late December, 2019 from seafood market of Wuhan, capital of the Hubei Province of China. Now it has circled the entire world by having exponential transmission rate human to human. Its transmission occurs through direct contact, aerosols and air droplets but it can also spread through shoes, clothes, electrical devices, etc. It cannot spread through house flies and mosquitoes. Until now, it has infected approximately 5.5 million people and caused 353334 deaths globally. Patients infected with COVID-19 harbor three sorts of symptoms; they may be asymptomatic, show mild or severe symptoms. Persons having medical complications like cardiovascular diseases, diabetes, kidney diseases, autoimmune diseases and other related diseases are more susceptible for serve illness or death. To reduce the damage associated with COVID-19, there should be complete implementation on recommendations provided by health care organizations and WHO which include avoiding close contact, wearing masks and gloves, practicing good hygienic measures and staying at home. Diagnosis can be made on the bases of epidemiological characteristics, screening and PCR. There is no FDA approved treatment available for COVID-19 right now but some antiviral drugs (Leponavir, Redimedisvir and Favipiravir), antimalarial potential drugs chloroquine or hypo chloroquine, Monoclonal antibodies, blood plasma transfer, stem cells, herbal treatments and many vaccines are also under considerations. Some vaccines like Moderna (mRNA-1273) are showing very fascinated results. Hopefully, it will be available at the end 2020 if it has passed all the clinical examinations. Recently, WHO stopped 
the clinical trials of chloroquine due to its severe complications observed in many patients related to heart, kidney and immune system.

\section{Introduction}

Coronaviruses are Nidovirales and belong to family of coronaviridae, and subfamily orthrocoronavirinae (Shereen, Khan, Kazmi, Bashir, \& Siddique, 2020). Coronavirus shows crown-like spikes on their outer surface; therefore, it was named as "Coronavirus". The Coronaviridae has the four subgroups Alpha, Beta, Gamma, and Delta $(\alpha, \beta, \gamma$ and $\delta$ ) coronaviruses(Zhong et al., 2003). The newly emerged SARS-CoV-2 belongs to $\beta$-coronaviruses, which is a enveloped, positive (+) sensed RNA virus (Su et al., 2016). SARS-CoV2 causes a highly contagious disease called Coronavirus Disease 2019 (COVID-19) (Adhikari et al., 2020). The phylogenetic studies shows that SARS-CoV-2 has high resemblance with Severe Acute Respiratory Syndrome virus (SARS-CoV) and the relatively poor resemblance with Middle East Respiratory Syndrome virus (MERS-CoV) (Shereen et al., 2020) (Wang et al., 2020). This is the $3^{\text {rd }}$ zoonotic coronavirus outbreak in the $1^{\text {st }}$ two decades of $21^{\text {st }}$ century. However, this time disease is rapidly transmitted from person to person and have raised a global human concern (Xie \& Chen, 2020). Human to human transmission through close contact, air droplets and asymptomatic incubation carriers within the families, friends and the community made it extremely contagious (Guo et al., 2020). By following exponential growth up to the end of January, 2020, outbreak reached to several countries grabbing considerable attention in the entire globe (Cucinotta \& Vanelli, 2020). As of March 11, 2020, WHO announced the epidemic to a global pandemic because of 13 folds increase in cases outside the China and number of affected countries also increased 3 folds. A further increase was is expected (Cucinotta \& Vanelli, 2020).

Unfortunately, the Chinese New Year festival "Lunar" holidays, which is celebrated on the beginning of new year, accord with the outbreak of COVID-19, is a best celebratory event of the year in China during which huge number of peoples' migration occurred towards their home towns (Cai et al., 2020). Approximately 3 billion people in China made close trips over the 40 days' travel period of "Chunyun". About 5 million individuals travelled from Wuhan, the epicentre of the COVID-19 outbreak, before the implementations of the travel ban on January 23, 2020 (Zu et al., 2020). Therefore, a rapid expansion and spread of COVID-19 cases transmission observed within the China and outside the China (Yang, Lu, et al., 2020). This review article highlights the ongoing challenges of COVID-19, pathogenesis, diagnosis, current and future treatment strategies, immune responses and future perspectives.

\section{Pathogenesis:}

The coronaviruses genome structure is best known among all RNA viruses of virosphere. Two-third (2/3) part of their genome (RNA) encodes for the viral polymerases (RdRp), material responsible for RNA synthesis, and two (II) big structural polypeptides are responsible for the host immune responses modulation (ORF1aORF1b). The remaining one-third (1/3) part of RNA encodes for four (IV) structural proteins. These structural proteins include spike (S) proteins, envelop (E) proteins, membrane (M) proteins, and nucleocapsid (N) proteins (Shereen et al., 2020). COVID-19 causes the infection of lower respiratory tract of human and results in pneumonia (Zhong et al., 2003). Patients infected with COVID-19 had the higher leukocyte count, respiratory abnormalities, and elevated levels of plasma proinflammatory cytokines (Cui, Li, \& Shi, 2019). Few patients can also face headache or hemoptysis and even relatively asymptomatic. According to Li et al; patients suffering from COVID-19 develop diarrhea (Klopfenstein et al., 2020) with loss of taste and smell (Menni et al., 2020). Coronavirus causes approximately $15 \%$ of adult common colds while the same strains of coronaviruses can cause debilitation and pneumonia in immunocompromised older adults (Nikolich-Zugich et al., 2020). Affected aged individuals with medical findings have a greater chance of respiratory failure due to severe lungs "alveolar" damage (Adhikari et al., 2020). These signs and symptoms are analogous with SARS-CoVs and MERS-CoVs infections. The bases of initial infections with SARS-CoV2 are not completely known until now. Although, pathogenesis mechanism of COVID-19 is inadequately learnt, however, the same mechanism of SARS-CoVs and MERS-CoVs can provide us huge information about the SARS-CoV-2 pathogenesis. Similarly, the attachment of SARS-CoV-2 with lung cells through ACE2 receptors lead to extended production of ACE2, which may catalyze the destruction of host alveolar 
cells. Injury to human alveolar cells run a group of systemic reactions and even death occurres (Hoffmann et al., 2020) as shown in figure 1. Generally, the coronavirus infection consists on attachment, entry, replication, translation, virion assembly and release of virus (Hoffmann et al., 2020) (Shirato, Kawase, \& Matsuyama, 2018).

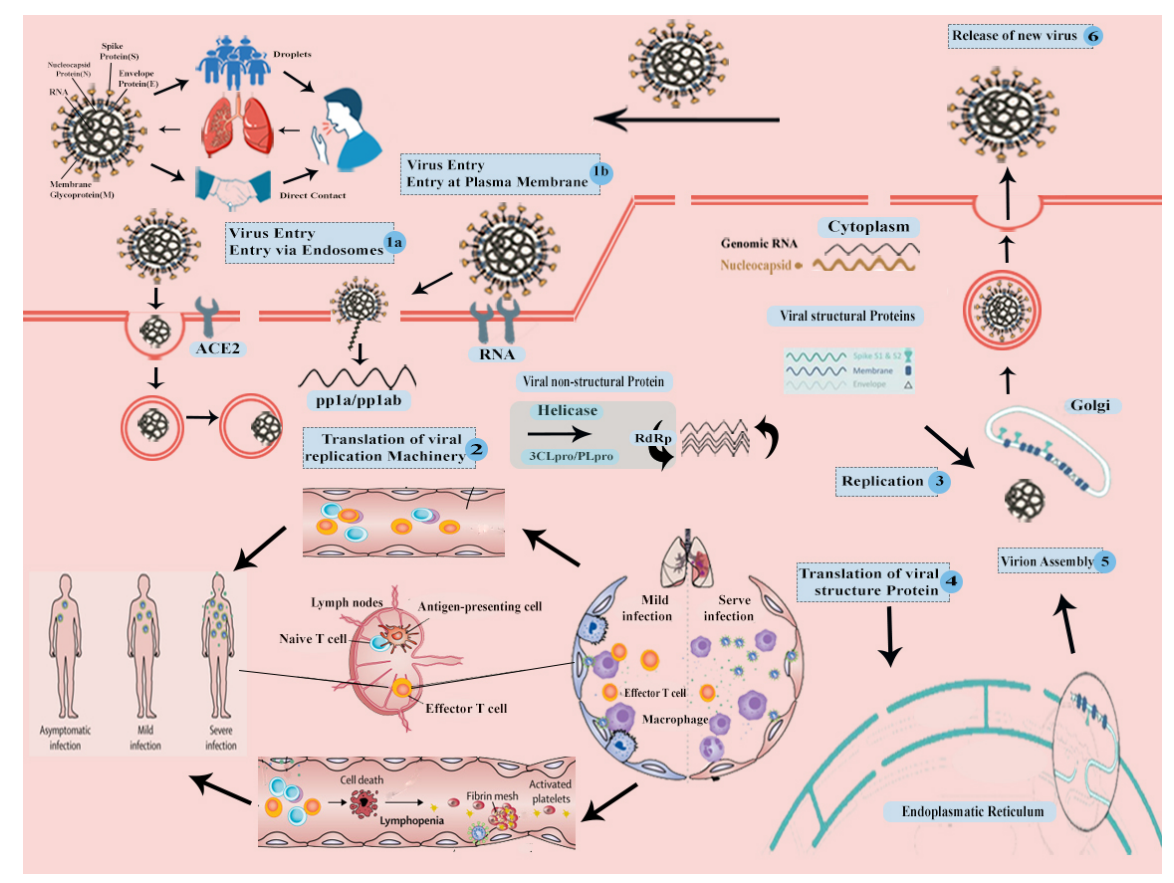

Figure 1: Person to person transmission of SARS-CoV-2 mainly depends upon air droplets and direct contact with infected person. After the transmission the viral particles undergo six step viral replication in human body such as 1) Viral entry through plasma membrane or endosomes 2) translation of viral replicating machinery 3) replication of viral particles 4) structural proteins translation 5) assembly of virion and 6) release of the viruses. Furthermore, the figure also explains the immune responses and conditions which develop after the infection. There are three types of infections; asymptomatic, mild and severe.

SARS-CoV-2 infection cycle starts from the entry of viral particle into the host cell. SARS-CoV-2 can enter into host cell in two ways; either through plasma membrane fusion or through endosomes (Hoffmann et al., 2020). When the virions enter in to the endosomes, L cathepsin activates the S protein. Although, the spike protein can also be activated by cellular serine protease TMPRSS2 in close proximity to the ACE2 receptor, that starts with the fusion of viral membrane and the plasma membrane (Hoffmann et al., 2020). Viral fusion entry less activates the immune system therefore, more efficient for viral replication (Shirato et al., 2018). The $\mathrm{S}$ proteins play a vital role in the attachment of virion with the host cell membrane (Ramanathan et al., 2020). It consists of two basic subunits S1 and S2. The S1 subunit consists on a signal peptide (SP) which is proceeded through Receptor Binding domain (RBD) and N-terminal domain (NTD), while S2 subunit consists on the I and II heptad repeat (HR), cytoplasmic domain (CPD), Transmembrane domain (TMD), and fusion peptide (FP) (Cai et al., 2020). Genome encoding initiates after the entry into human cells (respiratory tract cells) and facilitates the expression of genes (protein synthesis) which run the adaptation of CoVs to their human host (Su et al., 2016).

\subsection{Replication and translation of SAR-CoV-2 Machinery:}

When SARS-CoV-2 enters the body, it releases its RNA into the host lung cells, and polypeptides immediately undergo translation. Nonstructural proteins (NPs), that have a very important function in viral RNA and structural proteins' synthesis, have a very critical role in virion assembly formed by the viral genomic 
RNA encoding. Pp1a and pplab are the first polypeptides that are translated to form functional NSPs as helicase or RdRp (Shin, Jung, Kim, Baric, \& Go, 2018).

\subsection{Translation of viral structural proteins, virion assembly and Release:}

RdRp are very important enzymes that are responsible for the replication of viral structural proteins of RNA. S1, S2, E and M are structural proteins translated via ribosomes that are attached with endoplasmic reticulum (ER) and expressed on its surface as preparation of virion assembly. N proteins remain in cytoplasm and are assembled from genomic RNA. They bound to the virion precursor which is then transported via small vesicles from the ER through Golgi Apparatus to cell surface (Zhong et al., 2003). Virions are then released from the infected cell through exocytosis which then search for another host cell to infect.

\section{Immune response:}

Immune system shows response against COVID-19 into 2 distinct phases (I, II). Phase I immune response initiates during the incubation and non-severe stage of SAR-CoV-2. Fully functional and specific adaptive immune response is required to eliminate SAR-CoV-2 and to stop the disease progression to severe stages. At this stage of disease, anti-sera and IFN $\alpha$ treatments are important strategies for the protective endogenous immune response. Host generally has good health and appropriate immune genetic background that produce excellent antiviral immunity (Shi et al., 2020). When the protective immune response is failed to elicit the disease, the virus propagates to a severe stage and triggers the phase II immune response. Phase II immune response includes severe cytokines storms and pro-inflammation (Guo et al., 2020). According to Lancet reports, the prime factor of causalities with COVID-19 is the progression of acute respiratory distress syndrome (ARDS) (Kalkeri, Goebel, \& Sharma, 2020). One of the key mechanism of ARDS is the massive release of cytokines named as cytokines storm which leads to abandoned systemic inflammation due to the release of IFN- $\alpha$, IFN-g, IL-1b, IL-6, IL-12, IL-18, Il-33, TNF- $\alpha$, and TGFb and many other chemokines CCL2, CCL3, CCL5, CXCL8, and CXCL-10, etc. (Ahmed, Shah, Rahim, Flores, \& O'Linn, 2020). This lead to multi-organ failures like kidney and lungs (Ahmed et al., 2020), while the immune system of aged persons bear many age-related consequences that effect nearly each component of immune system collectively termed as immune senescence (Nikolich-Zugich et al., 2020). It changes the face themselves and enhance the morbidity and mortality rate with infectious diseases especially COVID-19 which affect both adaptive and innate immune system as well as the cooperation of immune response itself in time and space which work effectively in young adults but deteriorate with age. Globally, cytokines signalling, peroxide production, nitric oxide and phagocytic functions of neutrophils all are reduced in older people (Nikolich-Žugich, 2018). The macrophages ability of phagocytoses also become limited due to defective phosphorylation of activating enzymes to limit and delay cytokines secretions (Desai, Grolleau-Julius, \& Yung, 2010). Age related changes disturb the functionality of dendritic cell (DC, s), to encompass reduced uptake of antigen and diminish the maturation, migration and formulation of co-stimulatory molecules and necessary cytokines for $\mathrm{T}$ cells stimulations (Nikolich-Žugich, 2018). Furthermore, adaptive immune system is also significantly affected by age related factors. It diminishes both, B and T cells functions. Activation of old B cells face serious issues in the initiation of a vital E47 and AID transcription factor.

Improper induction of these important enzymes, in case of class switching and somatic cell hyper-mutation, head to decrease avidity of antibodies in aged patients (Nikolich-Žugich, 2018). T -cells are also affected enormously by age related changes and the proliferation of T-cells and expression of IL-2 is also reduced. $\mathrm{CD} 4^{+} \mathrm{TN}$ cells in old humans, whereby, diminish T-cells receptors' (TCR) signalling and population increment were associated with age linked destruction of miR-181, an important microRNA 53. MicroRNA commonly suppresses the phosphatase that attenuate TCR signalling. T-helper cells and downstream effector molecules like TNF, TNF- $\gamma$, granzyme B cells and others are also reduced (Nikolich-Zugich et al., 2020). A brief information is beyond this review scope, although, the aggregation of these alterations leaves aged people particularly susceptible to emerging infectious disease. This is, because, with advancing age, $\mathrm{T}$ and B-cells production starts dropping and at the age of 40-50 years, only $10 \%$ of T-cells are left as compared to the children and youngsters. This is the reason that why elderly people are more prone to infections (Chinn, Blackburn, Manley, \& Sempowski, 2012). 


\section{CURRENT TREATMENT STRATIGIES FOR COVID-19:}

To date, there is no specific antiviral drug and vaccine recommended for the treatment of COVID-19, however, UK and Germany are trailing their vaccines against COVID-19. The only treatment available is oxygen therapy which constitute the prime treatment intervention for patients with serious respiratory infections. Moreover, among other therapeutic strategies and a number of drugs, only a few have been used on patients with SARS-CoV and MERS-CoV infections and a few are being tested including remdisivir, baricitnib, hydroxychloroquine and the drugs used against influenza, favipiravir, chloroquine and others being considered (Chinn et al., 2012).

Wang et al. disclosed that chloroquine (anti-malarial drug) in combination with remdesivir is highly effective against the COVID-19., because chloroquine results great in in-vitro impacts on the suppression of uncoating of viruses. It does not allow a virus to uncoat and release its genome. It also inhibits alteration of posttranslational changes of newly synthesized proteins, it also does suppression of glycosylation in several viruses, including human immunodeficieny virus (HIV) (Wang et al., 2020). The advantage of exploring such drugs is that there is already a large number of information available about the bases of their usage and safety in humans and it is important that despite the urgency, the introduction of new therapies should not be pressed at the expense of safety. Moreover, Chinese traditional medicines have gained wide adoption, particularly in curing mild symptoms of COVID-19. A Chinese patent medicine Lianhuaqingwen (LH), which is formed of 13 herbs has played a positive role in the treatment of COVID-19 as it exerts broad spectrum impact on the group of influenza viruses by restricting viral propagation (Runfeng et al., 2020). Furthermore, immunotherapy by applying IgG in combination with antiviral drugs can be applied to treat and prevent COVID-19 and to make the immune response stronger against this virus. The IgG may be applied to neutralize the virus causing COVID-19 and the efficacy of IgG antibodies would be best if they were isolated from patients recovered from COVID-19 (Jawhara, 2020).

A research which include four rhesus monkeys introduce that formulating SARS-CoV-2 saved against future reoccurring of infections. When scientists re-infected II of the IV monkeys by this virus after 28 days of initial infection, a total of 96 anal swabs and nasopharyngeal swabs resulted negative (-ve) after the reexposure of SARS-CoV-2. The euthanasia and necropsy findings of I of the II monkeys confirmed these results. These results suggested that immune response raised by II animals have saved them from future infection of SARS-CoV-2. Hoffmann et al; studied, whether antibodies produced by patients who have been previously diagnosed positive $(+)$ for SARS would prevent SARS-CoV-2 entry into the cell. They also analysed that the antibodies against SARS-CoV S protein limit how well in the in-vitro model virus with a SARS-CoV-2 S protein could infect cells (Golchin, Seyedjafari, \& Ardeshirylajimi, 2020). They also saw similar findings with antibodies against $\mathrm{S}$ proteins produced in rabbits. These findings showed that neutralizing antibody responses formed against SARS-CoVs could offer some safety against SARS-CoV2 infection, which can be used for the prevention of COVID-19 infection (Hofmann \& Pöhlmann, 2004). Moreover, the passive immunization with convalescent sera having (Ab)antibodies from individuals who have recovered from COVID-19, could prevent COVID-19 infection as argued by Casadevall and Pirofski (Golchin et al., 2020). Some investigational treatments for COVID-19 are given in table 1.

To reduce the damage linked to COVID-19, global public health and infection control programs are exigently needed to bound the world wide transmission of virus. In COVID-19 victim's travel history has great significance for early discovery and isolation of SARS-CoV-2 pneumonia cases. It is necessary to reduce person to person transmission in order to limit secondary infections (Garami, 2020). Currently, prevention is the only strategy that can limit spread of COVID-19 (Anderson, Heesterbeek, Klinkenberg, \& Hollingsworth, 2020).

Table 1: Investigational treatments of COVID-19

VIRAL DRUGS UNDER CLINICAL TRIALS:

Leponavir and ritonavir (Stower, 2020)

Remedisvir (Grein et al., 2020)

Favipiravir (Cai et al., 2020)
POSSIBILITIES OTHER THAN

Monoclonal antibodies isolation fr Blood plasma transfers (Duan et Stem cells (Golchin et al., 2020) 
VIRAL DRUGS UNDER CLINICAL TRIALS:

POSSIBILITIES OTHER THAN

Chloroquine (Principi \& Esposito, 2020)

Hydroxychloroquine (Principi \& Esposito, 2020)

HERBAL TREATMENTS: 4 most commonly used herbs in China under trial are :

Astragali Radix (Huangqi) (Yang, Islam, Wang, Li, \& Chen, 2020)

HERBAL TREATMENTS: 4

Glycyrrhizae Radix Et Rhizoma (Gancao) (Luo et al., 2020)

Saposhnikoviae Radix (Fangfeng)

Lonicerae Japonicae Flo (Luo et a

\section{Chloroquine as a potential inhibitor among all other antivirals:}

Chloroquine (CQ) is an acidotropic amine form of quinine. For decades $\mathrm{CQ}$ is being used as a medication for the treatment and prevention of malaria and for a variety of other viruses such as human immuneodeficiency virus (HIV), Zika virus, Marburg virus, Dengue virus and SARS-CoV-1 (Barnard et al., 2006). The reason behind this frequent use is anti-inflammatory and immunomodulatory effects of this drug which can be beneficial in treating COVID-19. The China National Centre for Biotechnology Development found that CQ is I of the III drugs with encouraging profile against SARS-Cov-2 caused by COVID-19 (Devaux, Rolain, Colson, \& Raoult, 2020). Chloroquine has multiple mechanisms of action depending on the type of pathogen interaction. Chloroquine can limit the pre-entry step of viral replication cycle by interfering with viral particles binding to their intracellular receptors, it can also inhibit $\mathrm{pH}$ dependent endosome mediated entry of enveloped viruses (Barnard et al., 2006). This feature can be attributed in treating COVID-19 as SARSCoV-2 entry is also reported to be endosome mediated (Wang et al., 2020). The pH intonation by CQ can diminish the proper maturation of viral protein and recognition of viral antigens by receptors. CQ can also inhibit post translational modifications of viral proteins such as glycosylation which require low pH i.e. HIV and CQ increase the pH (Vincent et al., 2005). During in-vitro studies CQ has shown to deficit the glycosylation of angiotensin converting enzyme 2 (ACE2), a viral cell surface receptor (Wang et al., 2020). Chloroquine works at both, entry and after entry stages of COVID-19 infection. Its immune-modulating functions synergistically increase its antiviral effects on animals as it is mostly distributed in the entire body as well as lungs after oral administration. Recently CQ have been shown by several studies to reduce SARS-CoV-2 viral load and duration of viremia (Dong, Hu, \& Gao, 2020). Till now, 15 clinical trials have been conducted in China where each trial contained 100 patients to define the safety and efficacy of CQ in treating COVID-19, however, their immune modulatory effects also play a vital role in treating COVID-19 which require further investigation (Zhang, Wang, Qi, Shen, \& Li, 2020). Suddenly, on May 25, 2020 WHO suspended the clinical trials of chloroquine and hydroxyl-chloroquine as very potential treatment of COVID19 due to recent published study in Lancet by Mehra et al; According to their findings, chloroquine and hydroxyl-chloroquine showed serious side effects especially heart arrhythmia and many other complications related cardiovascular diseases (Klopfenstein et al., 2020).

\section{Vaccines:}

Currently, there is no FDA approved vaccine is available for COVID-19, but, several groups started their work on preparing vaccine shortly after Chinese scientists shared viral genetic material (Klopfenstein et al., 2020). These include, MODERNA, INOVIO, CUREVAC BIOTECH COMPANY and UNIVERSITY OF QUEENSLAND IN AUSTRALIA.

\section{MODERNA is a Key Forerunner among all Vaccines:}

At the end of March, 2020 this company started testing its mRNA-1273 vaccine against COVID-19 in Washington on 45 healthy volunteers with ages between 18-55, this mRNA vaccine when injected into human body cells, the lymphocytes (B and $\mathrm{T}$ cells) in lymph nodules can operate that mRNA initiates the formulation of protein in just the right way for other immune cells to mark and identify them for destruction (Grein et al., 2020). 


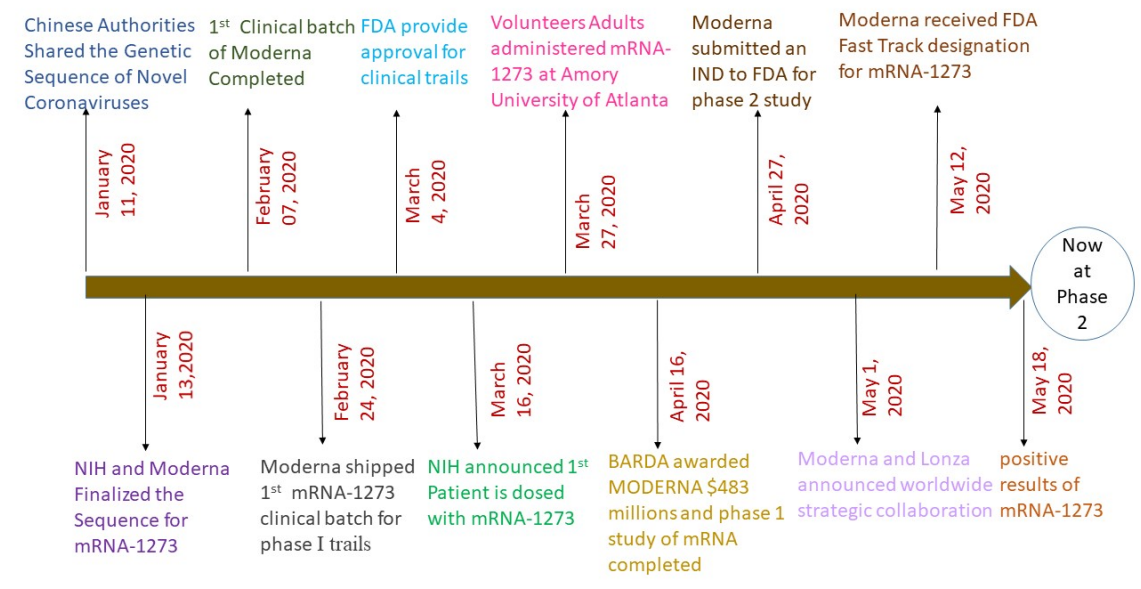

Figure 2: A timeline of Moderna mRNA-1273 vaccine.

This mRNA-1273 consists on the lipid Nano-particles (LNP), encapsulated mRNA vaccine that encodes for stabilized condition of $\mathrm{S}$ proteins before the fusion. The currently expected dose is $50 \mathrm{mcg}$. Moderna is ready to lunch Phase 3 studies by summer, 2020. Hopefully it would be the $1^{\text {st }}$ recommended vaccine against COVID-19 by the end of 2020 .

INOVIO : This company has quickly developed vaccine against COVID-19 as they are working since December on DNA vaccine for MERS, caused by the same coronavirus. The company is expected to start clinical trials of COVID-19 vaccine in May 2020 (Grein et al., 2020).

UNIVERSITY OF QUEENSLAND IN AUSTRALIA : Researchers are developing vaccine by growing viral proteins in cell culture. They expect to start clinical trials by the end of May 2020 (Duan et al., 2020).

CUREVAC BIOTECH : This company in Turbingen, Germany will begin a human trial of mRNA based vaccine in June 2020 (Kirkwood, 2019).

Another trial is by the Kaiser Permanente Washington Health Research institute in Seattle, USA, which is under consideration. In this trial, vaccine is injected to 45 healthy volunteers which contain a part of genetic material duplicated from SARS-CoV-2. Because this vaccine does not have the actual SARS-CoV-2, the individuals will not develop COVID-19 (Philippidis, 2020).

In UK, Sarah Gilbert and her colleague at Oxford University begin imminent trials on humans and animals of ChAdOx1 vaccine and it is predicted that the vaccine will be accessible in late of 2020 (Alharbi et al., 2017).

In China CanSino Biologics, in participation with the academy of Military Medical sciences, is also working to formulate the recombinant vaccine. A clinical trial has begun among 108 volunteers in Wuhan aged between 18-60 years (Cohen, 2020).

However, according to the director of the National institute of Allergy and Infectious Diseases, a vaccine won't be available for widespread use for at least another 12-18 months (Cai et al., 2020).

\section{Myths related to COVID-19:}

There are so many myths wondering around the world related to transmission, prevention and treatment of COVID-19. According to WHO, addition of pepper in food, inhalation of disinfectants, alcohols, bleach, exposure to hot sun, cold weathers, snows, bathing with hot water, hand dryer, UV-lights, watching nose with saline, eating garlic, older person susceptibility, vaccines of pneumonia and use of antibiotics cannot 
protect from this lethal virus. The only way of protection is to keep 1-meter distance. WHO also cleared that COVID-19 cannot spread through the house flies and bite of mosquitoes (Shereen et al., 2020).

\section{Conclusion and Future Perspectives:}

There is no proper treatment available for COVID-19 right now. Therefore, it is spreading rapidly across the globe and has already paralyzed life in a number of countries. Its spread can be limited only by having strict implementation on preventive strategies developed by WHO. Nowadays, it is too early to predict any practical situation, but it will strongly threat the entire world. Low-income countries like Pakistan, are facing worst-case scenarios by having very low economic support to fight against this lethal virus. This is an interesting and hot topic to develop guidelines, not only for the instant time of pandemic, but it is also very important to keep an eye on future as there are upcoming waves looking forward. There is a need for unveiling the detailed entry processes of SARS-CoV-2 into human cells. In addition, research work is required to fill the gaps associated with the transmission of the virus from zoonotic sources to humans. Without knowing the intermediate zoonotic source that had received the virus from source of origin and caused the infection in humans, it is almost impossible to eradicate the infection. Proper strategies should be applied in healthcare settings with restriction of people to their homes to mitigate the spread.

\section{Conflict of Interest: No}

Data Availability Statement: The authors confirm that the data supporting the findings of this study are available within the article and its supplementary materials.

Ethical Statement: The authors confirm that the ethical policies of the journal, as noted on the journal's author guidelines page, have been adhered to. No ethical approval was required as this is a review article with no original research data.

\section{References:}

Adhikari, S. P., Meng, S., Wu, Y.-J., Mao, Y.-P., Ye, R.-X., Wang, Q.-Z., . . . Raat, H. (2020). Epidemiology, causes, clinical manifestation and diagnosis, prevention and control of coronavirus disease (COVID-19) during the early outbreak period: a scoping review.Infectious diseases of poverty, 9 (1), 1-12.

Ahmed, T., Shah, R. J., Rahim, S. E. G., Flores, M., \& O'Linn, A. (2020). Coronavirus Disease 2019 (COVID-19) Complicated by Acute Respiratory Distress Syndrome: An Internist's Perspective. Cureus, 12 (3).

Alharbi, N. K., Padron-Regalado, E., Thompson, C. P., Kupke, A., Wells, D., Sloan, M. A., . . Warimwe, G. (2017). ChAdOx1 and MVA based vaccine candidates against MERS-CoV elicit neutralising antibodies and cellular immune responses in mice. Vaccine, 35 (30), 3780-3788.

Anderson, R. M., Heesterbeek, H., Klinkenberg, D., \& Hollingsworth, T. D. (2020). How will country-based mitigation measures influence the course of the COVID-19 epidemic? The Lancet, 395 (10228), 931-934.

Ang, L., Lee, H. W., Kim, A., Lee, J. A., Zhang, J., \& Lee, M. S. (2020). Herbal medicine for treatment of children diagnosed with COVID-19: A review of guidelines. Complementary therapies in clinical practice, 39 , 101174-101174. doi:10.1016/j.ctcp.2020.101174

Barnard, D. L., Day, C. W., Bailey, K., Heiner, M., Montgomery, R., Lauridsen, L., . . . Sidwell, R. W. (2006). Evaluation of immunomodulators, interferons and known in vitro SARS-coV inhibitors for inhibition of SARS-coV replication in BALB/c mice. Antiviral Chemistry and Chemotherapy, 17 (5), 275-284.

Cai, Q., Yang, M., Liu, D., Chen, J., Shu, D., Xia, J., . . . Yang, Y. (2020). Experimental treatment with favipiravir for COVID-19: an open-label control study. Engineering .

Chinn, I. K., Blackburn, C. C., Manley, N. R., \& Sempowski, G. D. (2012). Changes in primary lymphoid organs with aging. Paper presented at the Seminars in immunology. 
Cohen, J. (2020). Vaccine designers take first shots at COVID-19: American Association for the Advancement of Science.

Cucinotta, D., \& Vanelli, M. (2020). WHO declares COVID-19 a pandemic.Acta bio-medica: Atenei Parmensis, 91 (1), 157-160.

Cui, J., Li, F., \& Shi, Z.-L. (2019). Origin and evolution of pathogenic coronaviruses. Nature reviews Microbiology, 17 (3), 181-192.

Desai, A., Grolleau-Julius, A., \& Yung, R. (2010). Leukocyte function in the aging immune system. Journal of leukocyte biology, 87 (6), 1001-1009.

Devaux, C. A., Rolain, J. M., Colson, P., \& Raoult, D. (2020). New insights on the antiviral effects of chloroquine against coronavirus: what to expect for COVID-19? Int $J$ Antimicrob Agents, 55 (5), 105938. doi:10.1016/j.ijantimicag.2020.105938

Dong, L., Hu, S., \& Gao, J. (2020). Discovering drugs to treat coronavirus disease 2019 (COVID-19). Drug discoveries 83 therapeutics, 14 (1), 58-60.

Duan, K., Liu, B., Li, C., Zhang, H., Yu, T., Qu, J., . . . Hu, Y. (2020). Effectiveness of convalescent plasma therapy in severe COVID-19 patients. Proceedings of the National Academy of Sciences, 117 (17), 9490-9496.

Garami, A. R. (2020). Preventing a covid-19 pandemic-is there a magic bullet to save COVID-19 patients? We can give it a try. BMJ Comments. BMJ, 368 .

Golchin, A., Seyedjafari, E., \& Ardeshirylajimi, A. (2020). Mesenchymal stem cell therapy for COVID-19: present or future. Stem Cell Reviews and Reports , 1-7.

Grein, J., Ohmagari, N., Shin, D., Diaz, G., Asperges, E., Castagna, A., . . . Lescure, F.-X. (2020). Compassionate use of remdesivir for patients with severe Covid-19. New England Journal of Medicine .

Guo, Y.-R., Cao, Q.-D., Hong, Z.-S., Tan, Y.-Y., Chen, S.-D., Jin, H.-J., . . . Yan, Y. (2020). The origin, transmission and clinical therapies on coronavirus disease 2019 (COVID-19) outbreak-an update on the status. Military Medical Research, 7 (1), 1-10.

Hoffmann, M., Kleine-Weber, H., Schroeder, S., Krüger, N., Herrler, T., Erichsen, S., . . Nitsche, A. (2020). SARS-CoV-2 cell entry depends on ACE2 and TMPRSS2 and is blocked by a clinically proven protease inhibitor. Cell .

Hofmann, H., \& Pöhlmann, S. (2004). Cellular entry of the SARS coronavirus. Trends in microbiology, 12 (10), 466-472.

Jawhara, S. (2020). Could Intravenous immunoglobulin collected from recovered coronavirus patients protect against COVID-19 and strengthen the immune system of new patients? International journal of molecular sciences, 21 (7), 2272.

Kalkeri, R., Goebel, S., \& Sharma, G. D. (2020). SARS-CoV-2 Shedding from Asymptomatic Patients: Contribution of Potential Extrapulmonary Tissue Reservoirs. The American Journal of Tropical Medicine and Hygiene, tpmd200279.

Kirkwood, A. (2019). The reality of virtual pharmaceutical companies.Drug Discovery , 11.

Klopfenstein, T., N'dri Juliette Kadiane-Oussou, P., Royer, Y., Toko, L., Gendrin, V., \& Zayet, S. (2020). Diarrhea: an underestimated symptom in coronavirus disease 2019. Clinics and Research in Hepatology and Gastroenterology .

Luo, H., Tang, Q.-1., Shang, Y.-x., Liang, S.-b., Yang, M., Robinson, N., \& Liu, J.-p. (2020). Can Chinese medicine be used for prevention of corona virus disease 2019 (COVID-19)? A review of historical classics, research evidence and current prevention programs. Chinese journal of integrative medicine, 1-8. 
Menni, C., Valdes, A., Freydin, M. B., Ganesh, S., Moustafa, J. E.-S., Visconti, A., . . Falchi, M. (2020). Loss of smell and taste in combination with other symptoms is a strong predictor of COVID-19 infection. MedRxiv .

Nikolich-Žugich, J. (2018). The twilight of immunity: emerging concepts in aging of the immune system. Nature immunology, 19 (1), 10-19.

Nikolich-Zugich, J., Knox, K. S., Rios, C. T., Natt, B., Bhattacharya, D., \& Fain, M. J. (2020). SARSCoV-2 and COVID-19 in older adults: what we may expect regarding pathogenesis, immune responses, and outcomes. GeroScience , 1-10.

Philippidis, A. (2020). COVID-19: Top 60 Drug Treatments in Development: The biopharma industry is ramping up the development of dozens of potential drug therapies and clinical testing in an all-hands effort to combat the pandemic. Genetic Engineering 85 Biotechnology News, 40 (4), 10-13.

Principi, N., \& Esposito, S. (2020). Chloroquine or hydroxychloroquine for prophylaxis of COVID-19. The Lancet Infectious Diseases .

Ramanathan, K., Antognini, D., Combes, A., Paden, M., Zakhary, B., Ogino, M., . . . Shekar, K. (2020). Planning and provision of ECMO services for severe ARDS during the COVID-19 pandemic and other outbreaks of emerging infectious diseases. The Lancet. Respiratory medicine, 8 (5), 518-526. doi:10.1016/S22132600(20)30121-1

Runfeng, L., Yunlong, H., Jicheng, H., Weiqi, P., Qinhai, M., Yongxia, S., . . . Zifeng, Y. (2020). Lianhuaqingwen exerts anti-viral and anti-inflammatory activity against novel coronavirus (SARS-CoV2).Pharmacological research, 156 , 104761. doi:10.1016/j.phrs.2020.104761

Shanmugaraj, B., Siriwattananon, K., Wangkanont, K., \& Phoolcharoen, W. (2020). Perspectives on monoclonal antibody therapy as potential therapeutic intervention for Coronavirus disease-19 (COVID-19).Asian Pac J Allergy Immunol, 38 (1), 10-18.

Shereen, M. A., Khan, S., Kazmi, A., Bashir, N., \& Siddique, R. (2020). COVID-19 infection: origin, transmission, and characteristics of human coronaviruses. Journal of Advanced Research .

Shi, Y., Wang, Y., Shao, C., Huang, J., Gan, J., Huang, X., . . . Melino, G. (2020). COVID-19 infection: the perspectives on immune responses: Nature Publishing Group.

Shin, J. S., Jung, E., Kim, M., Baric, R. S., \& Go, Y. Y. (2018). Saracatinib inhibits middle east respiratory syndrome-coronavirus replication in vitro. Viruses, 10 (6), 283.

Shirato, K., Kawase, M., \& Matsuyama, S. (2018). Wild-type human coronaviruses prefer cell-surface TMPRSS2 to endosomal cathepsins for cell entry. Virology, 517, 9-15.

Stower, H. (2020). Lopinavir-ritonavir in severe COVID-19. Nature Medicine, 26 (4), 465-465.

Su, S., Wong, G., Shi, W., Liu, J., Lai, A. C., Zhou, J., . . . Gao, G. F. (2016). Epidemiology, genetic recombination, and pathogenesis of coronaviruses. Trends in microbiology, 24 (6), 490-502.

Vincent, M. J., Bergeron, E., Benjannet, S., Erickson, B. R., Rollin, P. E., Ksiazek, T. G., . . . Nichol, S. T. (2005). Chloroquine is a potent inhibitor of SARS coronavirus infection and spread. Virology journal, 2 (1), 69.

Wang, M., Cao, R., Zhang, L., Yang, X., Liu, J., Xu, M., . . . Xiao, G. (2020). Remdesivir and chloroquine effectively inhibit the recently emerged novel coronavirus (2019-nCoV) in vitro. Cell research, 30 (3), 269271.

Xie, M., \& Chen, Q. (2020). Insight into 2019 novel coronavirus - an updated intrim review and lessons from SARS-CoV and MERS-CoV.International Journal of Infectious Diseases . 
Yang, Y., Islam, M. S., Wang, J., Li, Y., \& Chen, X. (2020). Traditional Chinese medicine in the treatment of patients infected with 2019-new coronavirus (SARS-CoV-2): a review and perspective.International journal of biological sciences, 16 (10), 1708.

Yang, Y., Lu, Q., Liu, M., Wang, Y., Zhang, A., Jalali, N., . . X Xu, B. (2020). Epidemiological and clinical features of the 2019 novel coronavirus outbreak in China. MedRxiv .

Zhang, Q., Wang, Y., Qi, C., Shen, L., \& Li, J. (2020). Clinical trial analysis of 2019-nCoV therapy registered in China. Journal of medical virology, 92 (6), 540-545.

Zhong, N., Zheng, B., Li, Y., Poon, L., Xie, Z., Chan, K., . . . Xie, J. (2003). Epidemiology and cause of severe acute respiratory syndrome (SARS) in Guangdong, People's Republic of China, in February, 2003. The Lancet, 362 (9393), 1353-1358.

Zu, Z. Y., Jiang, M. D., Xu, P. P., Chen, W., Ni, Q. Q., Lu, G. M., \& Zhang, L. J. (2020). Coronavirus disease 2019 (COVID-19): a perspective from China. Radiology, 200490.

Tables:

Table 1: Investigational treatments of COVID-19

VIRAL DRUGS UNDER CLINICAL TRIALS:

Leponavir and ritonavir (Stower, 2020)

Remedisvir (Grein et al., 2020)

Favipiravir (Cai et al., 2020)

Chloroquine (Principi \& Esposito, 2020)

Hydroxychloroquine (Principi \& Esposito, 2020)

HERBAL TREATMENTS: 4 most commonly used herbs in China under trial are :

Astragali Radix (Huangqi) (Yang, Islam, et al., 2020)

Glycyrrhizae Radix Et Rhizoma (Gancao) (Luo et al., 2020)
POSSIBILITIES OTHER THAN

Monoclonal antibodies isolation $\mathrm{fr}$ Blood plasma transfers (Duan et

Stem cells (Golchin et al., 2020)

HERBAL TREATMENTS: 4 Saposhnikoviae Radix (Fangfeng) Lonicerae Japonicae Flo (Luo et a

\section{Figures:}

Figure 1: Person to person transmission of SARS-CoV-2 mainly depends upon air droplets and direct contact with infected person. After the transmission the viral particles undergo six step viral replication in human body such as 1) Viral entry through plasma membrane or endosomes 2) translation of viral replicating machinery 3) replication of viral particles 4) structural proteins translation 5) assembly of virion and 6) release of the viruses. Furthermore, the figure also explains the immune responses and conditions which develop after the infection. There are three types of infections; asymptomatic, mild and severe. 


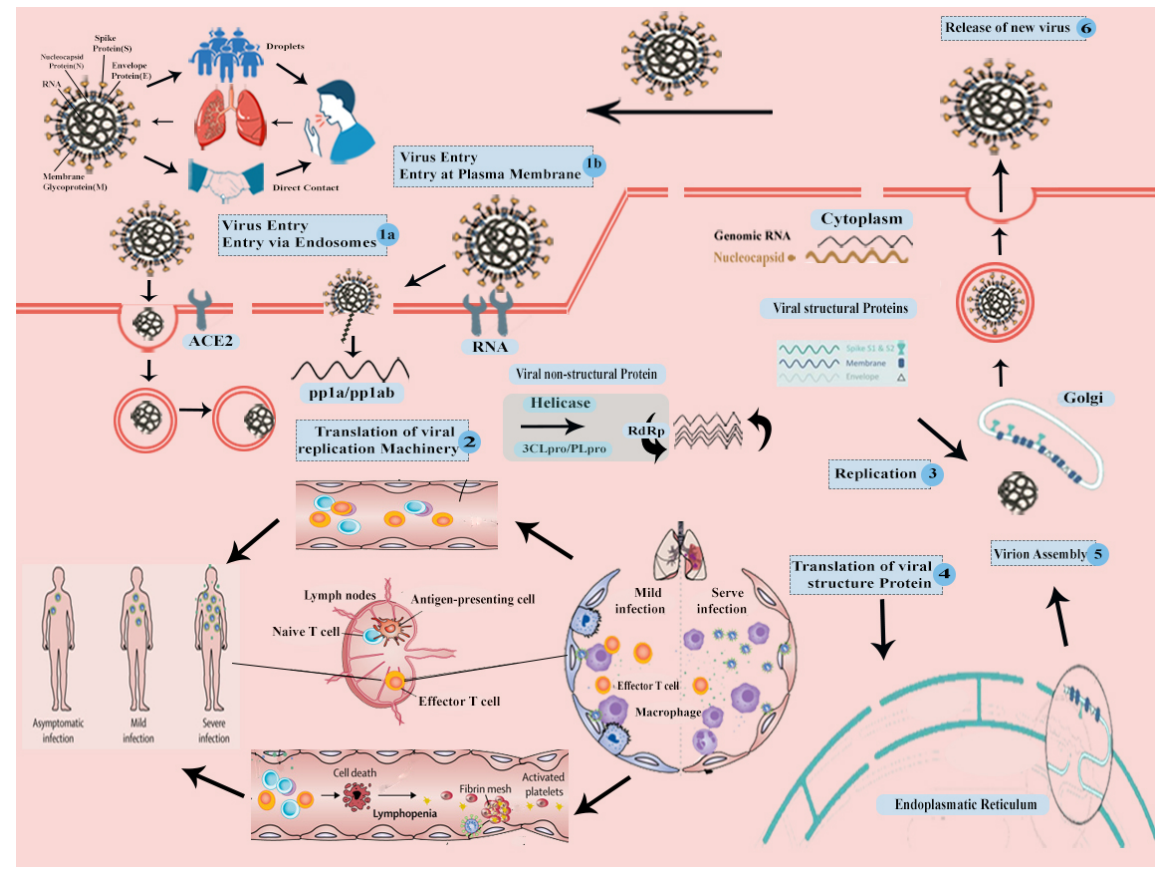

Figure 2: A timeline of Moderna mRNA-1273 vaccine.

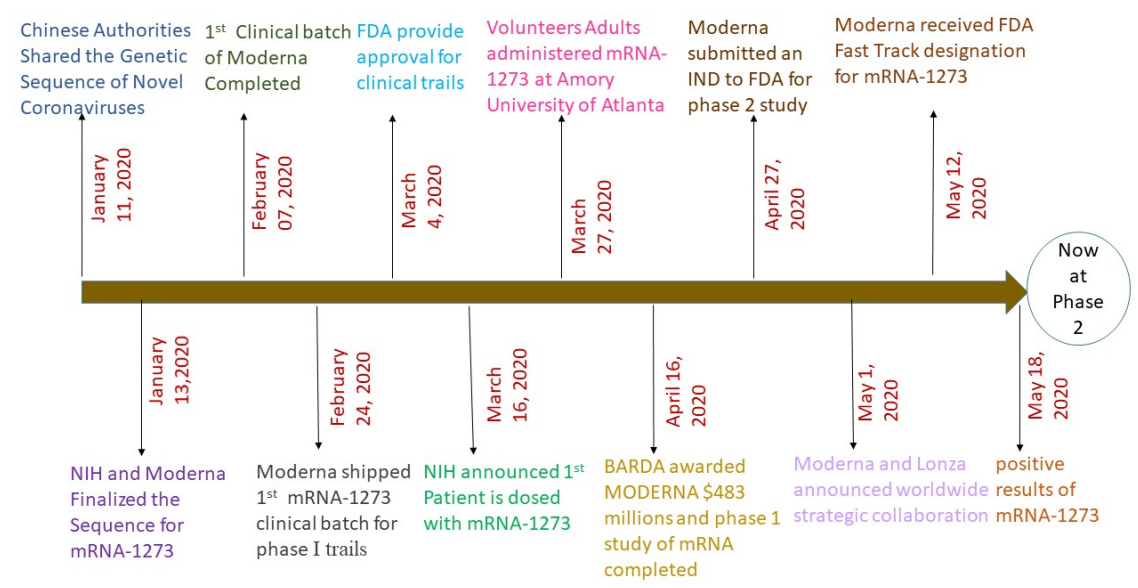

\section{Hosted file}

Figures.docx available at https://authorea.com/users/327853/articles/455249-pathogenesisdiagnosis-immune-responses-and-current-treatment-strategies-of-covid-19

\section{Hosted file}

Tables.docx available at https://authorea.com/users/327853/articles/455249-pathogenesisdiagnosis-immune-responses-and-current-treatment-strategies-of-covid-19 